\title{
Analysis of Role and Job Requirement about Middle Managers in China
}

\author{
Tongwei Song ${ }^{1}$, Anmin Wang ${ }^{2}$ \\ ${ }^{1,2}$ Xidian University, School of Economies and Management, No. 2 South Taibai Road, Xi'an, Shaanxi 710071, China
}

\begin{abstract}
Middle Managers are responsible for the rendering of decisions that affects the short-term performances of the firm. The role of the middle-level managers has been positioned through taking the proposal of corporate strategies at the beginning of this paper. This study examines the job descriptions and requirements posted for managers in China. Based on the data extracted from small, medium and large corporations, this paper found that the requirements relating to experience and academic preparations of Middle Managers are different. A deep analysis about job requirements including education background, personal abilities and work experience were been taken into consideration to measure the requirement for Middle Managers.
\end{abstract}

Keywords: Middle Managers, Corporate Strategies, Requirement, Job Descriptions

\section{Introduction}

Previous studies about organizational strategy paid more attention to the ability of senior managers for a long period of time. However, the significances of middle-level managers' role which occupies a central position in organizational hierarchies have always been ignored. Explorations of the identity of the middle managers always offer contradictory insights. Some scholars believe that middle managers are just those employers who execute corporate strategy but have nothing to do with strategic planning. Middle managers occupy a large proportion of the company's employees. They are generally regarded as a bridge between the top managers and junior staff, and their significances are also increasingly clear that sometimes the implementation effectiveness of middle managers determine the level of organization of execution. Under the increasingly complex business environment, in order to quickly adapt to market changes, it becomes more and more strictly for middle managers to be qualified.

Just taking the academic papers about middle managers and top managers on CNKI into consideration, it is not hard to find that more attentions was placed on senior officials than middle-level managers. Following figure will tell us the distance based on the data in CNKI from 1979 to 2015.

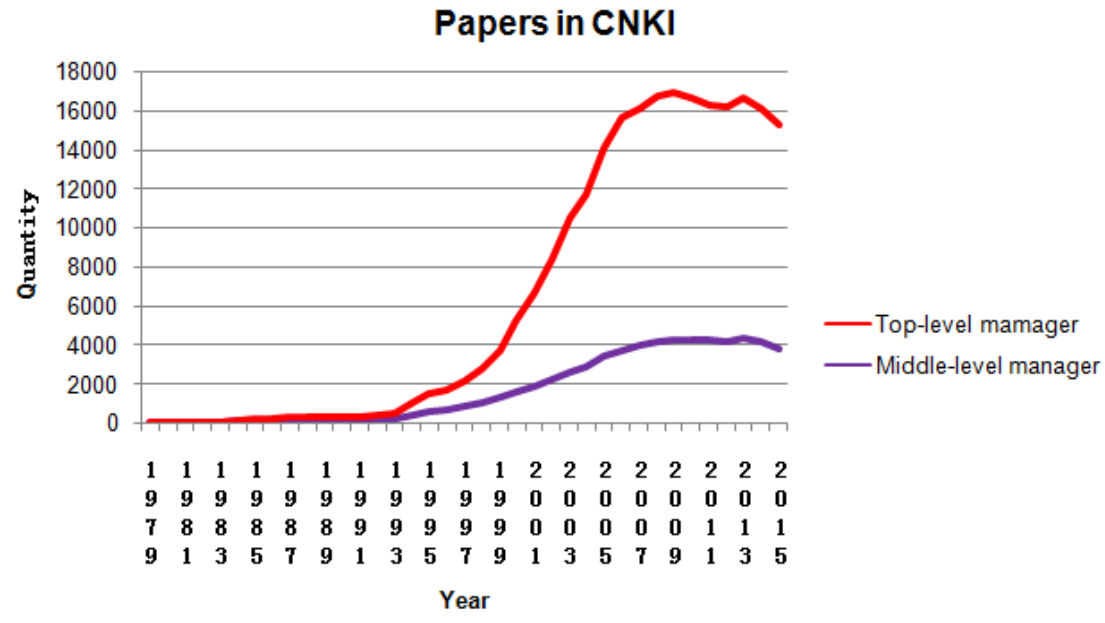

Figure 1: Comparation on academic attention between Middle-level and top team

\section{Middle Managers' Role and Competence}

\subsection{Middle managers' roles in enterprise}

What kind of roles middle managers play in the business activities of enterprise have not been clearly defined yet. Middle management, connecting the senior managers and junior staff, generally refers to managers who participate in the management activities. Their main responsibility is to implement the important decisions made by senior managers, supervise and coordinate junior managers to ensure the work effectively executed. "Pyramid" structure is usually applied in company personnel structure where senior managers are set at the top of the organizational structure and junior staffs are on the bottom. Although study for the business performance of middle managers is

Volume 5 Issue 7, July 2016 www.ijsr.net 


\section{International Journal of Science and Research (IJSR) \\ ISSN (Online): 2319-7064}

Index Copernicus Value (2013): 6.14 | Impact Factor (2015): 6.391

still a rarity, the significant role of middle managers is increasingly realized by entrepreneurs and scholars. Its' significance will be taken into consideration as much importance as Top managers in the future.

The former cognition of the role in middle-level managers has been explored by many domestic and foreign scholars. Middle-level managers are a bridge in the organization. They are both the manager and executor, and their main roles include the participant of the strategic decision, persons for information transmission, persons for coordination, supervisors and persons for feedback (Bai Yingchao, 2006).Middle and lower-level managers play a significant role in the strategic management processes, primarily in the execution stage. It is also important to learn more about processes associated with strategy execution in different organizations(John A. Parnell, 2008). middle managers' roles are categorized into four categories: entrepreneurship, executive, coach and coordinator. Roles of entrepreneurship are important to organizational development because they are related to middle managers' ability to make decision and their leadership behaviors. Executive role focuses on effective use of all kinds of recourse by middle managers to achieve organizational goals (Fan Yun, 2012). Middle-level managers as the important links of organizational management undertake important mission relating links between the preceding and following. They play the roles as firm performers of organizational decision, effective managers guiding the subordinates, positive participants of organizational culture construction, and fruitful self-governor (Chen Kehe, 2012). Integrity is relatively more important for the performance of top-level executives - roles middle-level managers may hold in the future(William A. Gentry, 2013).

The role of middle managers is positioned according to the main line under the implementation of corporate strategy in this paper. To better explore its importance, four roles are defined to describe middle managers in completely.

\section{(1)Decision Maker}

Corporate strategies are generally raised by the top managers who own the vast majority powers in enterprise. However, more and more enterprises begin to let middle managers participate in corporate strategy development and planning, and make them become as decision-making staff and assistants to put forward efficient reasonable proposal as much as possible. The reason why middle managers could play the role as decision maker is that they are more familiar with the business management activities in enterprise so that a better and more appropriate decision can be proposed. Meanwhile, middle managers just like a bridge set between the top managers and junior personnel, which are conducive to understand the emotional needs and changes in the perspective of the all employees. Collecting all kinds of information and intelligence is very complicated.

\section{(2)Strategy Implementer}

Middle managers also play the role as strategy implementer in enterprise. Efficient execution is an essential part for enterprises to have competitive advantages. Without executive power, it is hard to match a competence. Top managers are usually responsible for proposing development plans and strategies, while middle managers as the implementing body are the main executors of the strategy implementation. Ensuring the decision-implemented process goes on the way smoothly is one of most significant tasks for middle managers.

\section{(3)Information transmitter and coordinator}

Strategy and decision-making needs to be transmitted to junior staffs quickly and accurately, so that they can react accordingly in time. Owing to the different value for different level employees, sometimes there are some deviations for the lower-level employees to finish work. Middle managers shoulder this work like information transmitter and let all personnel understand the strategic intent completely. In addition, when problems and contradictions appear in every link, it is middle managers who serve as the organizational communicator and coordinator to eliminate them. With those coordinators, it is conductive to take the top managers' intention fully into account and realize the ideological unity for all employees.

\section{(4)Supervisor and Responder}

The proposed strategic decisions communicated to junior staff is not enough to complete the work target. Good implementation results and performances are the most valued in this whole process. Middle-level managers play the roles as supervisor to supervise the performance of junior staff and ensure that implementation is in good condition. Middle managers also play a role as responder to feedback the tasks process to Top managers, and provide corresponding effective advices. Based on the feedback of middle managers, corporate executives can conduct comprehensive and accurate performance assessments for employees.

\subsection{Middle managers' qualified conditions}

Researches on competence had slowly risen after 2000, especially in corporate management areas. Although scholars and entrepreneurs began to pay more attention to middle managers' competency, research literatures in this area are still relatively few. Therefore it would certainly like to become a popular research field in the future.

Middle-level leaders' competence has a great relationship with their cognitive ability, and it will affect the company's performance to some extent (King Adelaide Wilcox, 2001). Organization project performance has twelve core competencies in which managers think clam reaction ability and team management skills are the most valued (R.J. Dainty, 2004).With the using of Delphi method and manager questionnaire form, produce high-performance competency factors have been produced to explain significance of competency through system analysis(Wang Lu-jie, 2006).Competency has a close link with the position and work performance of employees, and it is the dynamic 


\section{International Journal of Science and Research (IJSR) \\ ISSN (Online): 2319-7064}

Index Copernicus Value (2013): 6.14 | Impact Factor (2015): 6.391

personal characteristics decide and distinguish work performance whether in a good situation (Wu Xiao-qin, 2007). Team building, communication, coordination, execution and continual learning are critical competencies for the success of middle managers in China(June Xuejun Qiao, 2009). Seven dimensions including personal quality, personal drive, knowledge, skills, innovation, relationship management, leadership and resilience can be analyzed to research middle managers' competency (Ni Yuan, 2012).

Competency is the foundation to judge whether a staff has the ability to perform organizational work or not. It is the collection of all employees' features such as skills, ideas, knowledge, motivation and personality, and it drives the organization employees to reach high performance with satisfaction. Team competency is the combination of a series of knowledge and techniques which were conducted in environment where team members affect and supplement for each other for a long time. Team competency is based on employees' personal competency. It is the reflection of individual competence, and finally sublimated into the organization's core competitiveness.

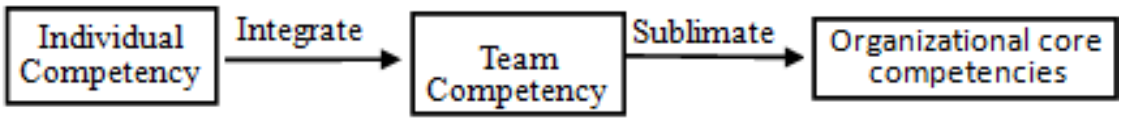

Figure 2: Competency transformation process

\section{Analysis for Job requirement of Middle Managers}

In order to analysis the competency of middle managers, this paper select middle managers' job recruitment information of 377 positions in 89 companies in China, which include 135 positions in 39 small companies, 113 positions in 19 middle companies and 129 positions in 31 big companies. We measure the competency of Middle Manager from three aspects such as educational background, management experience and some important personal characters.

\subsection{Educational Background}

Different types of enterprise have the different requirements for middle managers' educational background in different positions. These qualifications are generally divided into three categories: associate degree, bachelor degree and master degree. Though making an analysis and comparison to those 377 positions, we got the proportion of different education background in small, middle and big companies as shown in figure 3 below.

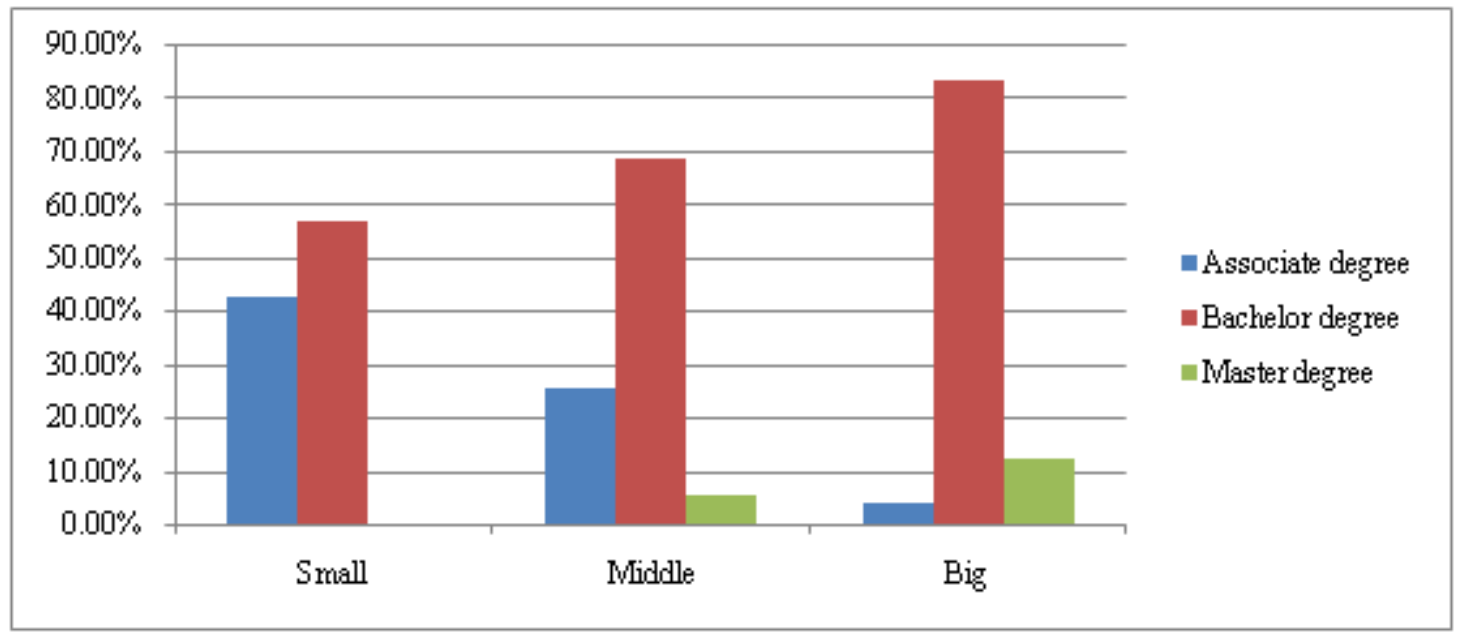

Figure 3: Requirements of different types of companies for degrees

It is not hard to find that the larger the company, the higher the degree required. Associate degree and bachelor degree occupy almost all the middle managers in small companies. In medium-size companies, bachelor degree is the main part and master degree is starting to be possessed. However, Bachelor degree occupies almost $80 \%$ in the large companies and master degree is more than associate degree.

\subsection{Management Experience}

Employees with very good working experience are very popular with the company especially to managerment Because work experence is a symbol to make sure that work flow and result are under control. This is no doupt that the higher position will be, the more rich work experence will be owned. Mangaement experence is one of the most important working experence for middle managers. However, considering the different strategy of different-sized companies, there are some distinctions in management experence. We get the requirement for middle managers' management experence based on the analysis and statistics of 377 middle managers' positions demand. 


\section{International Journal of Science and Research (IJSR) \\ ISSN (Online): 2319-7064}

Index Copernicus Value (2013): 6.14 | Impact Factor (2015): 6.391

Professional expertise means a series of basic cultural sciences and managements that are related to management activities and daily work in general science for middle managers. With the middle managers mastering expertise, management process will go better. On the figure 3 , this paper can summarize that the large the company, the more strict about management experience for middle managers.

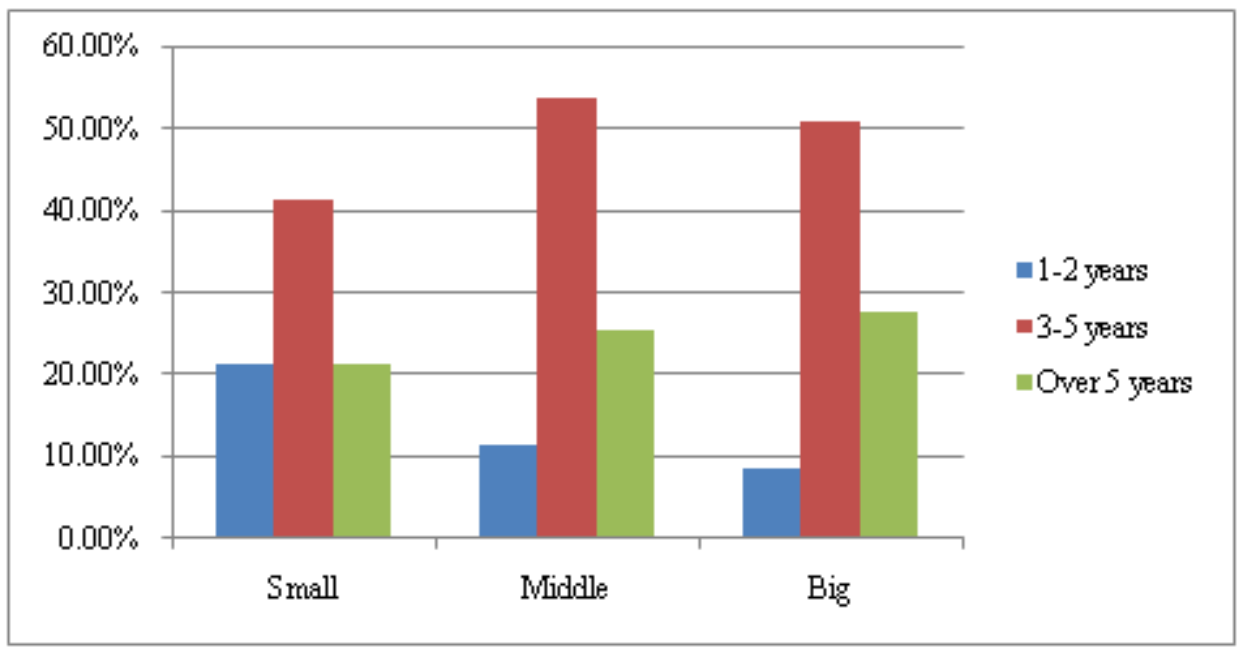

Figure 4: Requirements of different types of companies for management experience

\subsection{Middle managers' personal characters}

A qualified middle manager must have some good features or characters which constitude the competences for middle managers to finish the job well. Competency is a set of various personality characteristics which can drive staffs to produce outstanding work performance. It reflects the knowledge, skills, personalities and inner drives etc. It also can be expressed through different ways. What is needed to explain for this competency model is that the organizational teams need what kind of people who should possess what type of capacities or competences to do outstanding work.

By fully analyzing the job requirements in the 377 positions of middle managers, we found 17 characteristic elements that relate to the managers' ability. This study summarized these characteristics in the following table.
Table 1: Characteristics related to the job requirements of Middle Managers

\begin{tabular}{|c|c|c|c|}
\hline C1 & $\begin{array}{c}\text { Related Professional } \\
\text { Background }\end{array}$ & $\mathrm{C} 10$ & Ability to handle pressure \\
\hline C2 & Communication skills & $\mathrm{C} 11$ & Learning and Innovation \\
\hline C3 & $\begin{array}{c}\text { Familiarity with Work } \\
\text { Processes }\end{array}$ & $\mathrm{C} 12$ & Problem Solving \\
\hline C4 & $\begin{array}{c}\text { Analysis and Decision } \\
\text { Making }\end{array}$ & $\mathrm{C} 13$ & Logical thinking \\
\hline C5 & Teamwork & $\mathrm{C} 14$ & Vision \\
\hline C6 & Dedication and Hardwork & $\mathrm{C} 15$ & Collaborative \\
\hline C7 & Team leadership & $\mathrm{C} 16$ & Enterprising \\
\hline C8 & Personal character & $\mathrm{C} 17$ & Team Building \\
\hline C9 & Responsibility & & \\
\hline
\end{tabular}

By collecting the positions imformation obtained from the small, medium-sized and big companies, we made statistics of these 17 characteristics. In Figure 4 and Figure 5, it is simple and intuitive to see the proportion of these characteristics in different types of companies. 
International Journal of Science and Research (IJSR)

ISSN (Online): 2319-7064

Index Copernicus Value (2013): 6.14 | Impact Factor (2015): 6.391

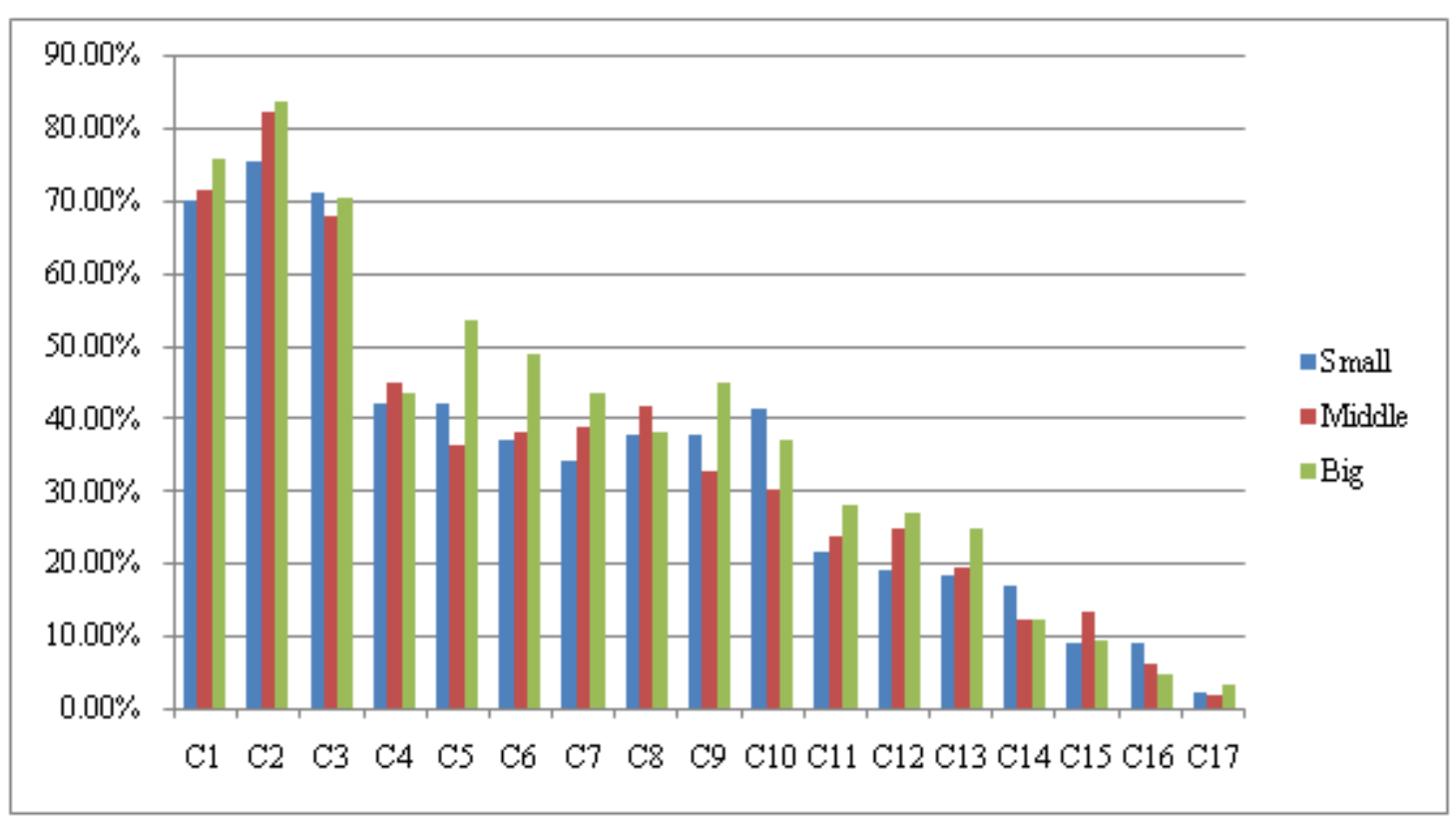

Figure 5: Proportion of 17 characteristics in three types of companies

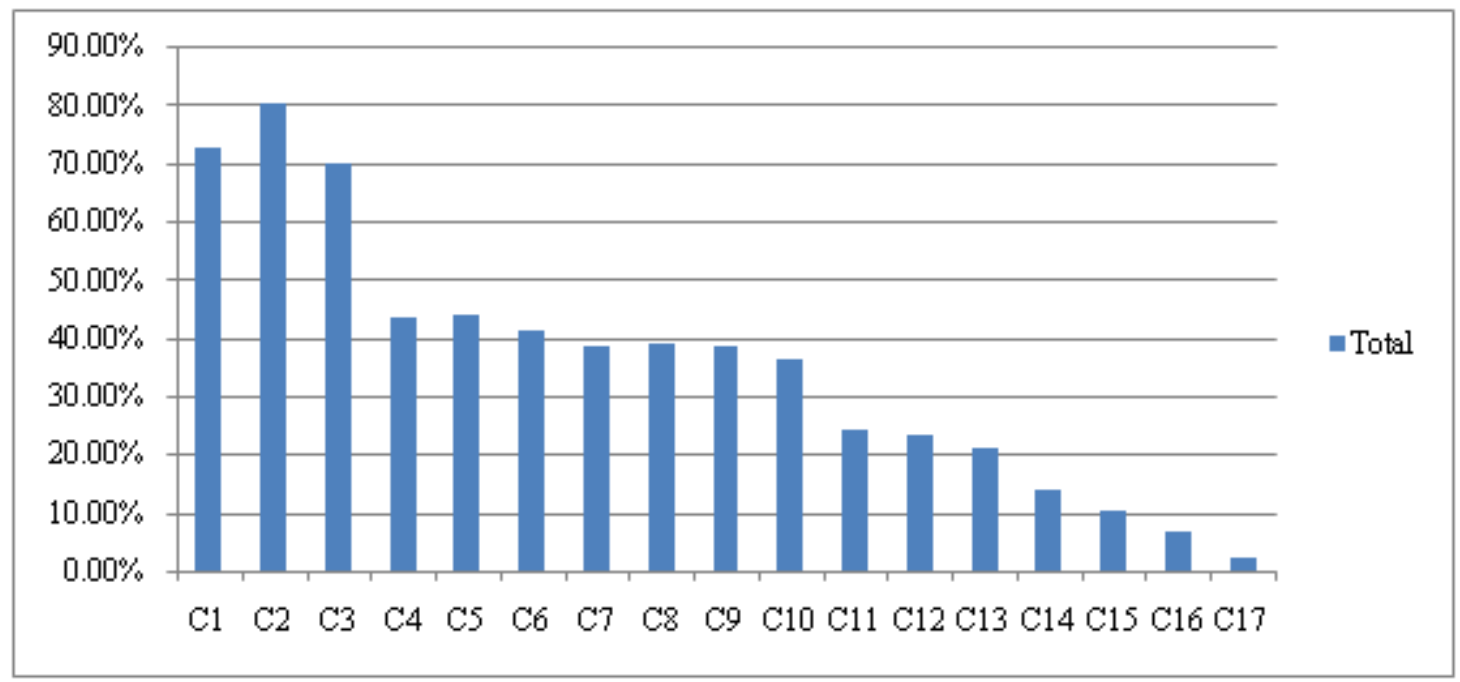

Figure 6: Total proportion of 17 characteristics in 377 positions requirements

It is obvious that these proportions present a certain trend. The proportion of Character1, Character2 and Character3 is greater than other characteristics. For Character4 to Character 10 , their proportions are very close and between $33 \%$ and $45 \%$. The others including Character 11 to Character17 are below 30\%. Job requirements for middle manegers in personal character has similar regular patterm in different size companies. The normalized samples are used to compare the difference and relevance in different size companies about characters. Result is showed lively as a Radar chart in figure 6. 


\section{International Journal of Science and Research (IJSR) \\ ISSN (Online): 2319-7064}

Index Copernicus Value (2013): 6.14 | Impact Factor (2015): 6.391

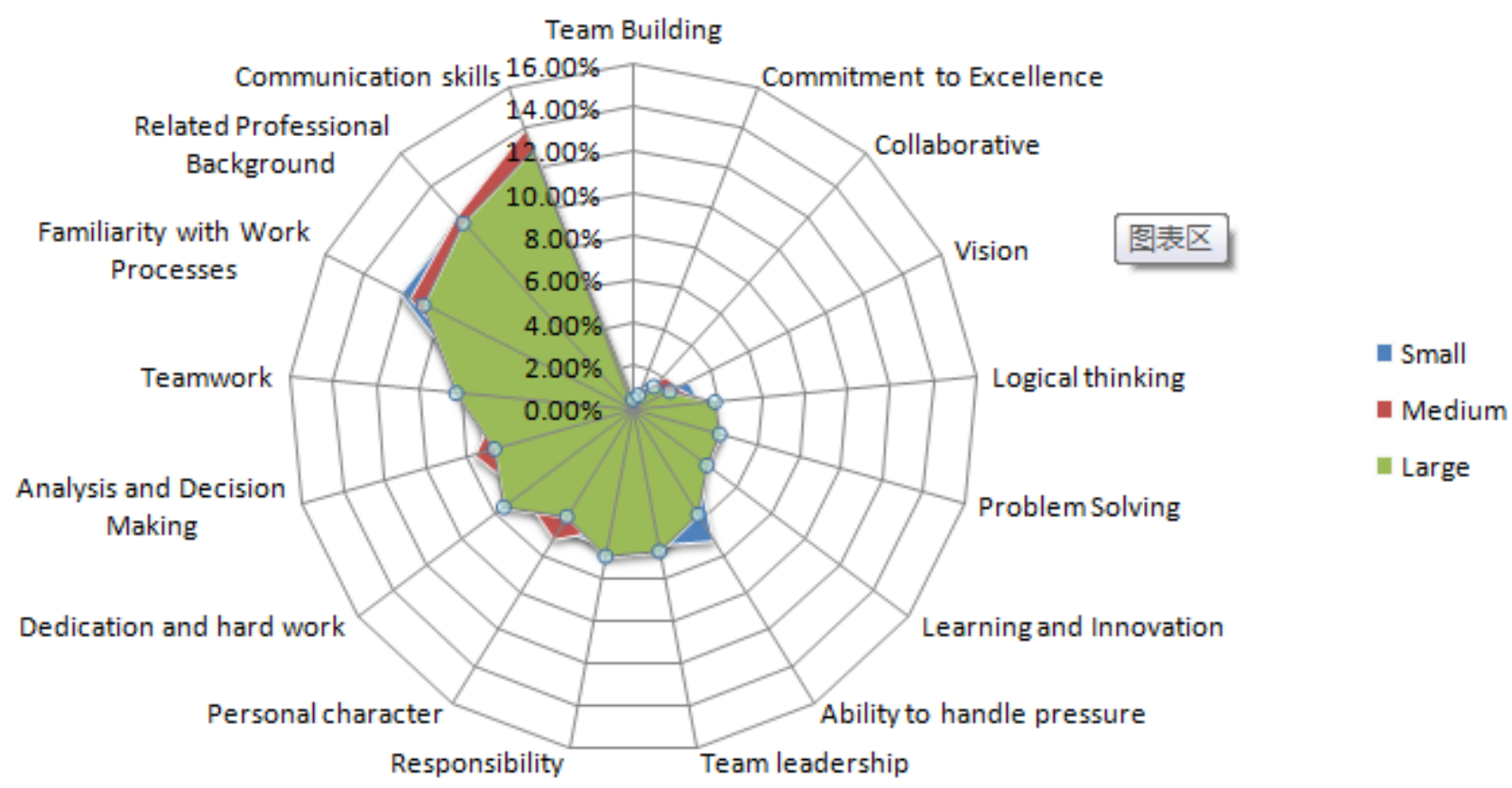

Figure 7: Comparison of all sorts of personal character in different companies

\subsection{Analysis Result}

Under the analysis above, those competencies characteristics can be divided into the following three key sections: Basic Ability, Important Ability and Extraordinary Ability.

Table 2: Middle-level managers' competence characteristics

\begin{tabular}{|c|c|c|c|}
\hline $\begin{array}{c}\text { Competence } \\
\text { Factors } \\
\end{array}$ & Basic Ability & $\begin{array}{c}\text { Important } \\
\text { Ability }\end{array}$ & $\begin{array}{l}\text { Extraordinary } \\
\text { Characteristics }\end{array}$ \\
\hline \multirow[b]{7}{*}{ Representation } & $\begin{array}{c}\text { Related } \\
\text { Professional } \\
\text { Background }\end{array}$ & $\begin{array}{c}\text { Analysis and } \\
\text { Decision } \\
\text { Making }\end{array}$ & $\begin{array}{c}\text { Learning and } \\
\text { Innovation }\end{array}$ \\
\hline & $\begin{array}{c}\text { Communication } \\
\text { skills }\end{array}$ & Teamwork & Problem Solving \\
\hline & $\begin{array}{l}\text { Familiarity } \\
\text { with Work } \\
\text { Processes } \\
\end{array}$ & $\begin{array}{c}\text { Dedication and } \\
\text { Hardworking } \\
\end{array}$ & Logical thinking \\
\hline & & $\begin{array}{c}\text { Team } \\
\text { leadership }\end{array}$ & Vision \\
\hline & & $\begin{array}{l}\text { Personal } \\
\text { character }\end{array}$ & Collaborative \\
\hline & & Responsibility & $\begin{array}{c}\text { Commitment to } \\
\text { Excellence } \\
\end{array}$ \\
\hline & & $\begin{array}{c}\text { Ability to } \\
\text { handle pressure }\end{array}$ & Team Building \\
\hline
\end{tabular}

\section{(1)Basic Ability}

Basic capacity, a significant capacity all managers need to possess, consists of three elements: related professional background, communication skills and familiarity with work processes.

These basic requirements are presupposition to do good management or to be qualified for every manager. For middle managers, it must ensure that they have those basic abilities excellently. Otherwise they couldn't complete the management work well. In the statistic communication skills is the highest proportion of all the middle managers' characteristics. Interpersonal skills are the ability to properly handle affairs among different people at work in a variety of relationships. The relationships are usually related to their superiors and subordinates. Good communication is the premise of teamwork. The more closely team agglomerate, the fewer staff conflicts will emerge and the faster organizational goals realize. Meanwhile, related professional background and familiarity with work processes are the two important basic abilities for middle managers. Only the managers are in the context of the relevant professional background, could they know what they are going to do. So familiarity with work processes not only make the management work implemented effectively and rapidly, but also reduce unnecessary risk and accidents mostly.

\section{(2)Important Ability}

Compared with Basic Ability, Important Ability is a higher level requirement for managers. In order not to lag behind other competitors, enterprises need those middle managers possessing Important Ability such as ability of analysis and decision-making, teamwork, dedication, team leadership, good personal character, responsibility and ability to handle pressure.

As a middle manager, you must have the basic ability

\section{Volume 5 Issue 7, July 2016 www.ijsr.net}




\section{International Journal of Science and Research (IJSR) \\ ISSN (Online): 2319-7064}

Index Copernicus Value (2013): 6.14 | Impact Factor (2015): 6.391

firstly. But if you want to be an excellent one, these important abilities above are indispensable. Leadership means the managers' unique leadership qualities, so that employees can be convinced. Personality characteristics or personality traits of middle managers are one of the most powerful weapons to access seniors' trust, let subordinates convinced and take team to be more cohesive. Corporate strategies are generally raised by the top managers. However, it is very necessary for middle managers to be involved in decision-making. To find and analysis the problems timely, and make suitable decisions. Decision-making capacity is the ability to make timely and accurate decisions based on a variety of objective circumstances or emergencies. Responsibility means that every member should show loyalty and love to their organization. Manager who insists his or her responsibility and value in each part on life or work is a really qualified manager. Middle managers are faced with increasing pressure on both superior and subordinate. Maintaining adaptability and passion is very important for middle managers. What's more, responsibility and personal characteristics play a significant role in middle managers' competence factors. A manager, filled with responsibility, honesty and strong professional ethics, can lead the team to a better future.

\section{(3)Extraordinary Ability}

Extraordinary Ability of middle-level managers could mainly be divided into seven aspects: Learning and Innovation, Problem Solving, Logical thinking, Vision, Collaborative, Commitment to Excellence and Team Building.

We live in a new information era where it is increasingly strict in managers' capability especially in Learning and Innovation. An enterprise will be eliminated if it can't keep up with the pace of the times. Relying on logical mind, managers will do better in the process of judging and reasoning. Creativity refers to the ability that one person can take good advantage of resources and personnel to create new ideas, innovative thinking or products. Life has never been a lack of opportunities but a lack of the ability to find it. Not only do managers need perception of information, but also enterprises do. Affinity makes the team's internal atmosphere more relaxing and makes employees work with a comfortable attitude. It is not enough for middle managers to finish the missions planned by top teams, they also need to play the role problem solving. To develop in the long term, the employees must to be a team. Middle managers who play the role as bridge between senior managers and junior staffs need to possess the ability of team building. What's more, middle managers need to possess vast vision. An enterprise couldn't go further under the leadership of short-sight managers. Middle managers need to keep an open field of horizons in knowledge, information or others, etc.

\section{Conclusions}

In 21 th century, competition among companies is ultimately reflected in the talent competition especially in the competition of middle managers who occupy the important central position in organizational hierarchies. For a long time, little attention has been paid to the middle-level manager' role in the enterprise while as a bridge between the top managers and junior staff, middle managers' significances are becoming increasingly clear. This paper research the middle managers in China from two aspects respectively. One is the role of middle managers in enterprise, and another is the job requirement.

Firstly, the role of middle managers is positioned according to the main line under the implementation of corporate strategy in this paper. To better explore its importance, four roles (Decision make, Information transmitter and coordinator, Strategy implementer and Supervisor) are defined to describe middle managers in completely.

Secondly, by collecting and analyzing the company recruitment information, we measure the competency of Middle Manager from three aspects such as educational background, management experience and some important personal characters. This paper finds that requirement for middle managers in education background and management experiences have big difference in different companies. However, it is very amazed to find that different size company has the similar regular pattern about the requirement in personal characters.

This paper is set out to study the important central position - middle manager which has always been ignored in a long time. The main significance drawn from this study concerns the importance of middle-level managers in the implementation of corporate strategy and points out the necessary characters, education background and work experience. It is conductive to the future more in-depth study about middle-level managers.

\section{References}

[1] John A. Parnell. Strategy execution in emerging economies: assessing strategic diffusion in Mexico and Peru”. Management Decision. 2008. Vol. 16 (9).

[2] Fan Yun. An empirical study of the influence of multiple role behaviors of middle managers on Corporate Performance". Journal of Industrial Engineering Management. pp.1-11, 2012. Vol.26 (2).

[3] Chen Ke-he. - The analysis of the organization confusion and the position of the middle managers", Human Resource. pp.96-99, 2012. Vol. 21(4).

[4] William A. Gentry \& Knstin. Integrity's place among the character strengths of middle-level managers and top-level executives". The Leadership Quarterly. pp.395-404, 2013, Vol. 24 (3).

[5] King Adelaide Wilcox, Fowler Sally. Managing organizational competencies for competitive advantage: The middle-management edge". The Academy of Management Executive, pp.95-106, 2001(2).

[6] Andrew R.J. Dainty, Mei - I Cheng. A competency based performance model for construction project 


\section{International Journal of Science and Research (IJSR) \\ ISSN (Online): 2319-7064}

Index Copernicus Value (2013): 6.14 | Impact Factor (2015): 6.391

managers -Construction Management \& Economies, pp.877-886, 2004(8).

[7] Wang Lu-jie, Research on competence of middle managers in Enterprises". Human Resource Management,pp.71-74,2006(2).

[8] Ni Ning, How to Apply Fuzzy-set Qualitative Comparative Analysis to Competency Modeling," Industrial Engineering \& Management. pp.109-113, 2009(14)

[9] Xu Hong-hua, Fraining system design for middle-level manager in core enterprises based on post competency model," Procedia Earth and Planetary Science. pp:1746-1771, 2009 (1).

[10]Ni Yuan, The evaluation model and empirical research on the competency of middle managers," Systems Engineering, pp.1-7. 2012 (1).

[11]Ching-Wen Chen,Chin-Tsang Ho, Tsung-Che Tsai. The moderation effect of slack resources on the relationships between CEO characteristics and R\&D expenditures,'Int. J. of Business and Systems Research, pp.357 - 374,2012(7).

[12] Kannan Nilakantan, Estimation of career progression and growth properties in Markov manpower systems with a competitive climate,'Int. J. of Business and Systems Research,pp.292 - 317,2013(7). Francis Kofi Andoh-Baidoo, Marco A. Villarreal, Kai S. Koong, Hector Cornejo, Nils Schmidt, Homer Colunga,

[13]Ruben Mesa, Key competencies for global project managers: a cross cultural study of the UK and India,'Int. J. of Business and Systems Research, pp.223 $-243,2011(5)$.

[14] C Curie,M Axelos,C Bardet and R Atanassova, "N ChaubetThe Impact of Human Resources Mind Management on Organizational Development through the Mediator Variable of Organizational Culture," International Journals of Research in Organizational Behavior \& Human Resource Management, pp.179-184,2013(1).

[15]K Alfes, C Truss, EC Soane, C Rees and M Gatenby,"The Relationship between Line Manager Behavior, Perceived HRM Practices, and Individual Performance: Examining the Mediating Role of Engagement,"Human Resource Management, pp.839-859,2013(52).

\section{Author Profile}

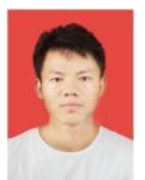

Tongwei Song received the B.S degree in Management from Tianjin Polytechnic University, and now is a Graduate Student in the School of Economics and Management, Xidian University, Xian, Shaanxi, China. His primary research interests are in the areas of human resources management, conflict management and management science. A recipient of many scholastic awards that were earned throughout his college career, Mr. Song is also a highly respected student leader on campus.

Anmin Wang is a Professor and Dean of the School of Economics and Management, Xidian University, Xi'an, Shaanxi, China. An expert in the areas of management science, decision analysis, and analytical modeling, he is a consultant to a variety of industries in Central China. Dr. Wang is well published and recognized within the academic community in China. Under his leadership, the School of Economics and Management at Xidian University has been awarded an increasing number of research centers and institutes. 